\title{
Reforma psiquiátrica: trajetória de redução dos leitos psiquiátricos no Brasil
}

\section{Psychiatric Reform: the path of psychiatric beds reduction in Brazil}

\author{
Sílvia Louzada Duarte* \\ Maria Lúcia Teixeira Garcia**
}

\begin{abstract}
Resumo: O objetivo deste artigo é refletir sobre o processo de redução de leitos psiquiátricos no interior do Movimento de Reforma Psiquiátrica Brasileira. Para isso, foi utilizada uma pesquisa documental a partir de relatórios de gestão, portarias da área técnica da saúde mental do Ministério da Saúde e dados do Instituto Brasileiro de Geografia e Estatística. O processo de luta pela melhoria nas condições de tratamento dispensado aos sujeitos com transtorno mental encontra muitas resistências e dificuldades, principalmente com a falta de investimento e de priorização da área de saúde mental. Como mecanismos para atingir tal objetivo, foram criados pelo Ministério da Saúde o Programa Nacional de Avaliação dos Serviços Hospitalares e o Programa Anual de Reestruturação da Assistência Psiquiátrica Hospitalar no Sistema Único de Saúde. Mas, apesar de alguns avanços, a Reforma Psiquiátrica ainda caminha a passos lentos.
\end{abstract}

Palavras-chave: Reforma Psiquiátrica. Política de redução de leitos psiquiátricos. Política de Saúde Mental.

\begin{abstract}
This article aim is to reflect upon the process of reduction of psychiatric bedswithin the Brazilian psychiatric reformmovement. To achieve this, a documental research from reports and ordinancesof the mental health technical area of Brazilian Health Ministry and Brazilian Institute of Geography and Statistics was used. The process of the fight for betterconditions of treatment of subjects with mental disorder meet many resistanceand difficulties, especially with the lack of investment sand prioritization of the mental health field. As mechanisms to achieve this goal the Brazilian Health Ministrycreated the National Program of Evaluation of the Hospital Services and the Program of Restructuring ofthe Psychiatric Care in Hospitals. Despite some advances, the Brazilian Psychiatric Reformstill walksat a slow pace.
\end{abstract}

Keywords: Psychiatric Reform. Psychiatric beds reduction policy. Mental Health Policy.

Recebido em: 01/06/2012. Aceito em: 24/05/2013.

\footnotetext{
* Graduanda em Serviço Social pela Universidade Federal do Espírito Santo (UFES). Vitória, Espírito Santo, Brasil. E-mail: silvinha_Id@ hotmail.com

** Doutora em Psicologia Social pela Universidade de São Paulo (USP). Professora do Programa de Pós-Graduação em Política Social e do Departamento de Serviço Social da Universidade Federal do Espírito Santo (UFES). Pesquisadora do CNPq e orientadora do trabalho. Vitória, Espírito Santo, Brasil. E-mail: lucia-garcia@uol.com.br
} 


\section{Introdução}

O presente trabalho tem por objetivo analisar como se deu o processo de redução progressiva de leitos psiquiátricos no Brasil no período entre 2002 e 2011. Esse recorte temporal decorreu da aprovação da Lei 10.216 (de 2001) e de sua implementação no país a partir de produção normativa do Ministério da Saúde (MS).

Para tanto, realizou-se uma pesquisa documental envolvendo as legislações do MS que normalizam o Programa Nacional de Avaliação dos Serviços Hospitalares (PNASH/psiquiatria) no país (ver Quadro 1).

Quadro 1 - Legislações analisadas (sistematização da autora)

continua

\begin{tabular}{|c|c|c|c|}
\hline Tipo de legislação & $\mathrm{N}^{0}$ & Ano & Assunto \\
\hline Portaria & 251 & 2002 & $\begin{array}{c}\text { Estabelece diretrizes e normas para a assistência hospitalar } \\
\text { em psiquiatria, reclassifica os hospitais psiquiátricos, define e } \\
\text { estrutura, a porta de entrada para as internações psiquiátricas } \\
\text { na rede do SUS e dá outras providências. }\end{array}$ \\
\hline Portaria & 10708 & 2003 & $\begin{array}{l}\text { Institui o auxílio-reabilitação psicossocial para pacientes } \\
\text { acometidos de transtornos mentais egressos de internações. } \\
\text { Tal auxílio faz parte do Programa De Volta para Casa. }\end{array}$ \\
\hline Portaria & 2077 & 2003 & Incentiva a reabilitação fora da unidade hospitalar. \\
\hline Portaria & 52 & 2004 & $\begin{array}{l}\text { Institui o Programa Anual de Reestruturação da Assistência } \\
\text { Psiquiátrica Hospitalar no SUS - } 2004 .\end{array}$ \\
\hline Portaria & 53 & 2004 & $\begin{array}{c}\text { Estabelece nova classificação dos hospitais psiquiátricos, } \\
\text { prevista no Programa Anual de Reestruturação da Assistência } \\
\text { Psiquiátrica Hospitalar no SUS - 2004, instituído pela Portaria } \\
\text { n.GM/MS 52/04. }\end{array}$ \\
\hline Portaria & 1102 & 2004 & $\begin{array}{l}\text { Prorroga, por } 60 \text { (sessenta) dias, o prazo de que trata o item } \\
5 \text { do anexo da Portaria n.52/gm, de } 20 \text { de janeiro de } 2004 \text {, } \\
\text { para a assinatura do termo de compromisso e ajustamento, } \\
\text { em que devem constar tanto as reduções de leitos da etapa de } \\
\text { retificações/ajustes de leitos, quanto as reduções de módulos } \\
\text { de } 40 \text { leitos, a ser realizadas até julho de } 2005 \text {, conforme } \\
\text { diretrizes do programa. }\end{array}$ \\
\hline Portaria & 1628 & 2004 & $\begin{array}{c}\text { Prorroga o prazo para assinatura de termo de Compromisso e } \\
\text { Ajustamento e retificação de ajuste de leitos. }\end{array}$ \\
\hline Portaria & 304 & 2005 & $\begin{array}{l}\text { Reclassifica os hospitais descritos no anexo desta Portaria, } \\
\text { depois de cumprida a segunda etapa de redução de leitos, } \\
\text { de acordo com o estabelecido na Portaria n.52/GM, de } 20 \text { de } \\
\text { janeiro de } 2004 \text {. }\end{array}$ \\
\hline Portaria & 395 & 2005 & $\begin{array}{c}\text { Determina que os hospitais psiquiátricos dos grupos II a IV, que } \\
\text { não aderiram ao Programa de reestruturação da Assistência } \\
\text { Psiquiátrica Hospitalar no SUS-2004, voltem a ser remunerados } \\
\text { conforme valores definidos na Portaria SAS n.77, de primeiro } \\
\text { de fevereiro de } 2002 .\end{array}$ \\
\hline Portaria & 1899 & 2008 & $\begin{array}{c}\text { Institui o Grupo de Trabalho sobre Saúde Mental em Hospitais } \\
\text { Gerais. }\end{array}$ \\
\hline Portaria & 2629 & 2009 & $\begin{array}{l}\text { Reajusta os valores dos procedimentos para a atenção em } \\
\text { saúde mental em Hospitais Gerais e incentiva internações de } \\
\text { curta duração. }\end{array}$ \\
\hline
\end{tabular}


Reforma psiquiátrica: trajetória de redução dos leitos psiquiátricos no Brasil

\begin{tabular}{|c|c|c|c|}
\hline Tipo de legislação & $\mathrm{N}^{\circ}$ & Ano & Assunto \\
\hline Portaria & 2644 & 2009 & $\begin{array}{c}\text { Estabelece novo reagrupamento de classes para os hospitais } \\
\text { psiquiátricos, reajusta os respectivos incrementos, cria } \\
\text { incentivos para internação de curta duração nos hospitais } \\
\text { psiquiátricos e dá outras providências. }\end{array}$ \\
\hline Portaria & 404 & 2009 & $\begin{array}{c}\text { Reclassifica os Hospitais Psiquiátricos nas Classes N I, N II, N } \\
\text { III e N IV. }\end{array}$ \\
\hline Portaria & 426 & 2009 & $\begin{array}{c}\text { Estabelece que hospitais indicados para descredenciamento } \\
\text { permaneçam nas classes em que se encontravam em outubro } \\
\text { de 2009. }\end{array}$ \\
\hline
\end{tabular}

Outras fontes documentais utilizadas foram: dados do Ministério da Saúde sobre a redução de leitos psiquiátricos públicos e privados, contidos emSaúde Mental em Dados 9(2011) e 10 (2012), os relatórios de gestão 2003-2006 e 2007-2010, assim como o Relatório Mundial de Saúde de 2002. Também foi consultado Instituto Brasileiro de Geografia e Estatística - IBGE (dados censitários dos estabelecimentos de saúde com internação).

Para a análise desse conjunto de dados, partiu-se da premissa de que o processo de redução dos leitos psiquiátricos é resultado de uma luta travada no Brasil e no mundo pela meIhoria nas condições de tratamento dispensado aos sujeitos com transtorno mental. Para tanto, a análise entende o papel e o lugar do Hospital Psiquiátrico (HP) na constituição do campo saúde mental e o processo de sua desconstrução através do Movimento pela Reforma Psiquiátrica (MRP) mundial e nacional. Este texto está estruturado em três partes: inicialmente, refletimos sobre o processo de expansão dos HPs no país, para, posteriormente, problematizar a Política de Saúde Mental no Brasil, na direção da redução dos leitos nessas instituições. Por fim, indicamos algumas das resistências a esse processo de redução e como isso interfere no avanço da Reforma Psiquiátrica (RP).

Nosso argumento traz intrínseco um compromisso político das pesquisadoras com a reafirmação dos princípios do movimento. Assim, buscamos desvelar o que está envolvido em torno dos dados sobre redução de leitos psiquiátricos no Brasil.

\section{Hospital psiquiátrico - expansão e redução, mas não eliminação}

Historicamente, os HPs são os principais responsáveis pelo tratamento e pela internação de pacientes com transtornos mentais, sendo consideradas instituições baseadas na prática da exclusão, da violência, da centralidade médico-hospitalar. Não se proporciona um tratamento qualificado ao paciente internado nesse tipo de hospital, muito menos se garantem os direitos dos sujeitos colocados sob sua tutela (BRASIL, 2007).

A discussão sobre os direitos civis, políticos e sociais dos ditos "loucos" é um tópico que atravessa o Movimento pela Reforma Psiquiátrica no Brasil e no mundo (AMARANTE, 1995). Apesar de toda a luta desse movimento, os hospitais ainda são hegemônicos, seja pela concentração de investimento feito em saúde mental, que é direcionado a ele, seja pela grande quantidade de instituições existentes, dificultando o processo de desinstitucionalização (MELO, 2005).

Tal situação é retratada pela Organização Mundial de Saúde (OMS) em seu Relatório Mundial de Saúde, onde se afirma: "os hospitais, de grande porte, são construídos tendo em vista mais o funcionamento econômico do que o tratamento" (OMS, 2002, p. 97).

A contestação aos métodos terapêuticos utilizados no interior dos HPs é alvo das reflexões e ações de Franco Basaglia na Itália, país que primeiro aprovou a Lei antimanicomial (em 1978) (AMARANTE, 1994; KILSZTAJNET et al., 2008). Oliveira (2011), refletindo sobre o pensamento de Franco Basaglia, afirma que os manicômios são instituições 
[...] onde a violência habitava e abafava qualquer resquício de vida que pudesse existir. Local que servia como regulador social, pois se fazia morada para a exclusão e opressão de tantos marginalizados sociais, vítimas da estigmatização e do sistema capitalista. O manicômio não passava de um depósito humano que agrupava uma série de pessoas que, dentre muitos estigmas que carregavam, também eram ditas improdutivas para toda uma sociedade (OLIVEIRA, 2011, grifos nossos).

Ainda em relação às resistências ao modelo tradicional de tratamento psiquiátrico centrado nos HPs, destacou-se no Brasil a psiquiatra Nise da Silveira. Contrapondo-se aos tratamentos utilizados (eletrochoques, lobotomia e camisas-de-força químicas), Nise criou, na década de 1950, a Casa das Palmeiras, um centro de atenção psicossocial em regime de externato marcado pela existência de portas e janelas abertas (KILSZTAJN et al., 2008).
Essa ação isolada de Nise da Silveira deve ser contextualizada no processo de expansão dos HPs registrado entre 1941 e 1961 (Tabela 1). Essa expansão representa o também a expansão do modelo médico assistencial privatista, no qual o setor privado foi o principal prestador de serviços da assistência médica. Desde a década de 1980, registram-se tentativas governamentais de redução de leitos psiquiátricos no país.

$\mathrm{Na}$ Tabela 1, observa-se a disparidade na oferta de leitos psiquiátricos em hospitais públicos e privados ao longo dos anos. Entre a década de 1960 e 1970, os HPs privados (HPP) quase triplicaram em relação aos públicos. Na década de 1980, o número de instituições aumentou para cada 4,9 HPP, havia um público. Na década de 1990, a redução no número de hospitais, tanto de públicos quanto de privados, não alterou a relação entre estes (para cada 4,8 HPP havia um público). Em 2009, essa relação ficou assim representada: 1,3 hospitais psiquiátricos públicos para 1 HPP (BRASIL, 2009a).

Tabela 1 - Evolução do número de hospitais psiquiátricos, por natureza, 1941/1997

\begin{tabular}{c|c|c|c|c}
\hline Ano & Hospital público & Hospital privado & \multicolumn{1}{c|}{ Total } & Relação público-privado \\
\hline 1941 & 23 & 39 & 62 & $1: 1,6$ \\
1961 & 54 & 81 & 135 & $1: 1,5$ \\
1971 & 72 & 269 & 341 & $1: 3,7$ \\
1981 & 73 & 357 & 430 & $1: 4,9$ \\
1991 & 54 & 259 & 313 & $1: 4,8$ \\
1997 & 45 & 211 & 256 & $1: 4,7$ \\
\hline
\end{tabular}

Fonte: SIH/VAL-AIH/DATASUS.

Se, por um lado, a diminuição do número deHPs ocorreu em resposta ao MRP, por outro, isso explicita o embate entre dois projetos em curso: o da indústria da loucura e do MRP. No Brasil, o Movimento pela Reforma Psiquiátrica iniciou sua ação na década de 1970, mas só foi regulamentado em 2001, com a Lei 10.216/2001, que "dispõe sobre a proteção e os direitos das pessoas portadoras de transtornos mentais e redireciona o modelo assistencial em saúde mental" (BRASIL, 2001, sp).

Esse trajeto de luta é longo e inconcluso. Isso acontece, por um lado, devido ao contexto político-econômico atual, ou seja, com a adoção de políticas neoliberais, com redução da intervenção do Estado no plano social, enxugamento e redução dos gastos e financiamentos gover- namentais nos serviços públicos e nas políticas sociais (MELO, 2005).

Há ainda a resistência dos donos de HPs em abrir mão do lucro e dos investimentos que recebem por prestar serviços assistenciais. Com isso, há um rebatimento no andamento da Reforma Psiquiátrica, pois, para o alcance de seus objetivos, tem de haver a criação e a ampliação de uma rede de base extra-hospitalar. Para tanto, há a necessidade de investimentos e a inversão dos gastos - aumento dos investimentos em serviços extra-hospitalares e diminuição dos gastos nos hospitais privados.

Porém, o orçamento do MS destinado à saúde mental ainda é mínimo e irregular. Há anos, os gastos em saúde mental correspondem 
entre 2,2 e $2,9 \%$ dos gastos totais com a saúde (GARCIA, 2011).

Como tentativa de melhorar o investimento na área da saúde, foi criada a Emenda Constitucional (EC) n.29, que estabeleceu a base de cálculo e os percentuais mínimos de recursos orçamentários que a União, os Estados, o Distrito Federal e os Municípios são obrigados a aplicar em ações e serviços públicos de saúde (BRASIL, 2000). Para Marques e Ferreira (2009), a EC 29 é um importante ganho para a saúde, pois vem diminuir a instabilidade no financiamento que essa política enfrenta desde a promulgação da Constituição de 1988 (que previa que 30\% do orçamento da Seguridade Social deveriam ser destinados ao SUS, o que não aconteceu) (MARQUES; FERREIRA, 2009). Mas só em 2012 a EC 29 foi sancionada pela presidente Dilma. Segundo o texto, a União deverá aplicar na saúde o valor empenhado no ano anterior, acrescida da variação nominal do Produto Interno Bruto (PIB). Já os estados e o Distrito Federal deverão investir $12 \%$ de sua receita, enquanto os municípios devem investir 15\%.Mas, segundo especialistas e militantes na área, essa medida não resolverá os graves problemas da saúde pública (MENDES, 2012).
A saúde pública no Brasil sofre com a insuficiência de recursos investidos. Segundo Santos e Carvalho (2011, sp),

Estamos com um dos mais baixos financiamentos públicos de saúde: segundo a OMS, em 2008 estávamos com 3,7\% do PIB correspondendo ao financiamento público da saúde. Países com os melhores sistemas públicos de saúde estavam com a média de $7,1 \%$. Nosso per capita público anual para a saúde estava em U\$385 (padronizados pelo poder de compra para comparações internacionais), enquanto aqueles países estavam com a média de US\$ 2.530. É de se destacar que perdemos até na América Latina, para a Argentina, o Chile, a Costa Rica e o Uruguai, com os per capitas de 757, 479, 708 e 619 respectivamente, ainda bem baixos, mas que, para serem igualados pelo Brasil, é necessário acrescentar entre $R \$ 20$ e 50 bilhões ao atual orçamento do nosso Ministério da Saúde de $\mathrm{R} \$ 71,5$ bilhões.

Se, por um lado, o financiamento feito pela União é baixo, por outro, o investimento em saúde, por parte dos estados e dos municípios, está crescendo.

Tabela 2 - Participação percentual nos gastos com saúde

\begin{tabular}{c|c|c|c}
\hline \multicolumn{3}{c|}{ RECEITA \% DA SAÚDE POR ESFERA DE GOVERNO - BRASIL - 1980-2009 - SIOPS+MS } \\
\hline ANO & $\%$ UNIÃO & \% ESTADOS & \% MUNICÍPIOS \\
\hline 1980 & $75,00 \%$ & $17,80 \%$ & $7,20 \%$ \\
\hline 1995 & 63,80 & 18,80 & 17,40 \\
\hline 2000 & 59,74 & 18,53 & 21,73 \\
\hline 2001 & 56,17 & 20,67 & 23,16 \\
\hline 2002 & 53,11 & 21,64 & 25,25 \\
\hline 2003 & 50,69 & 22,80 & 25,24 \\
\hline 2004 & 51,14 & 23,62 & 25,24 \\
\hline 2005 & 50,64 & 24,48 & 24,98 \\
\hline 2006 & 46,70 & 26,12 & 27,18 \\
\hline 2007 & 46,95 & 25,77 & 27,27 \\
\hline 2008 & 47,14 & 25,94 & 26,91 \\
\hline 2009 & 45,67 & 26,77 & 27,56 \\
\hline
\end{tabular}

Fonte: 2007 - MF; 2008-2009 - Estimativa MF (desenvolvido por Gilson Carvalho).

De 1980 a 2009, os gastos de Estados e municípios somados aumentaram mais de duas vezes (Tabela 2). Se, por um lado, "estima-se que os recursos arrecadados, depois das transferências constitucionais, fiquem $60 \%$ com a União, $24 \%$ com os Estados e $16 \%$ com os Municípios" 
(Mendes, 2012, sp), por outro, os dados indicam claramente o processo de desfinanciamento federal da saúde. Assim, o governo federal está transferindo gastos e responsabilidades para Estados e municípios. Por sua vez, estes estão arcando com a maior parte dos gastos em saúde no Brasil, devido aos cortes no orçamento que a União vem realizando nos últimos anos na área de saúde para o pagamento da dívida externa. Dessa forma, Mendes (2012) conclui: os municípios são o ente da federação que menos arrecada e que mais gasta com saúde.

Outro ponto a ser destacado é a forma de financiamento prevista na Constituição de 1988 para a Seguridade Social - representada pelas políticas de saúde, pela previdência e pela assistência social. O financiamento deveria ser feito com recursos provenientes da União, Estados e municípios, do Distrito Federal, de contribuições de empregadores, assim como dos trabalhadores, além de $50 \%$ da receita de concursos e loteria (MARQUES; MENDES, 2009). Porém, o que se observa é que o gasto federal com a Seguridade Social diminui cada vez mais e, na área da saúde, podemos destacar algumas causas principais para isso: a) o pagamento da dívida pública $e$ sua amortização, priorizada a partir da crise fiscal nos anos 1970, - principalmente após 2000, quando o total das despesas de capital chegou a mais de $90 \%$; b) o capital financeiro que hoje domina e sustenta a política econômica; c) a "suposta" crise na Previdência Social, entre 1993 e 1994, quando havia uma baixa arrecadação das contribuições de empregados e empregadores -embora ainda assim essa arrecadação representasseuma das principais fontes de financiamento da saúde entre 1993 e 2005; d) a política macroeconômica dos governos FHC e Lula (MARQUES; MENDES, 2009). Tudo isso impede a devida aplicação dos recursos e reflete o descaso por parte do governo na saúde pública, impactando as condições de financiamento e funcionamento do Sistema Único de Saúde (SUS).

A saúde não é "um produto de mercado comercializável entre os que têm poder aquisitivo" (BRASIL, 2005, p. 20). Mas, tratada como um produto, ela deixa de efetivar um dos princípios do SUS: a universalidade do acesso. Assim, como ocorre na área de saúde em geral, a saúde mental acaba se tornando um meio de lucratividade e, na maioria das vezes, o acesso ao tratamento é mais rápido para aqueles que pagam pelos serviços.

Na saúde mental, a cobertura do atendimento abrange $72 \%$ da população (BRASIL, 2012). Isso significa que a rede de saúde mental hoje existente nega assistência a $28 \%$ da população - que não têm assegurado esse direito constitucional. Outro ponto a ser observado é a distribuição dos serviços no território brasileiro: nem todos os estados possuem cobertura, por exemplo, de CAPSi (Centro de Atenção Psicossocial para Infância e Adolescência). É o caso de Acre, Amazonas, Rondônia, Roraima e Tocantins. No Amazonas, também falta o CAPS AD (Centro de Atenção Psicossocial Álcool e Drogas). Esses serviços concentram-se principalmente nas regiões Sul e Sudeste (BRASIL, 2005). Também não existem residências terapêuticas no Tocantins e no Pará, porém lá elas estão em processo de implantação (Brasil, 2012).

Todos esses dados nos levam a uma constatação: a Reforma Psiquiátrica caracteriza-se por um processo em curso, marcado por um trajeto lento e recente - o que também ocorre em outros países, ou seja, essa não é uma particularidade brasileira. Assim como no Brasil, a política de saúde mental com a oferta de cuidados extra-hospitalares de base comunitária para pacientes com transtornos mentais em muitos países não constitui uma prioridade. $O$ financiamento e o treinamento para profissionais que atuam na área são insuficientes, fazendo que a cobertura nesse ramo da saúdenão seja completa (OMS, 2002).

A Lei que estrutura a Política de Saúde Mental no Brasil surge como um importante ganho para todos os que defendem a RP. Os dados da Organização Mundial de Saúde (WHO, 2011) indicam que $60 \%$ dos países membros possuem legislação em saúde mental (cobrindo $72 \%$ de toda a população mundial). Essas legislações foram aprovadas principalmente após o ano 2000, e vêm crescendo significativamente após 2005 (WHO, 2011). ${ }^{1}$

\footnotetext{
${ }^{1}$ O Gráfico 1 apresenta os dados da OMS agrupados por regiões e por Grupo de renda proposto pelo Banco Mundial (as economias foram divididas pelo crescimento anual da renda per capita). Assim, AFR representa os países africanos; AMR representa América; EMR, Leste do Mediterrâneo; EUR representa Europa; SEAR equivale a Sul e Leste Asiático; WRP, representa Oeste do Pacífico.
} 
Gráfico 1 - Avanço nas políticas de saúde mental entre 2000 e 2005 por região

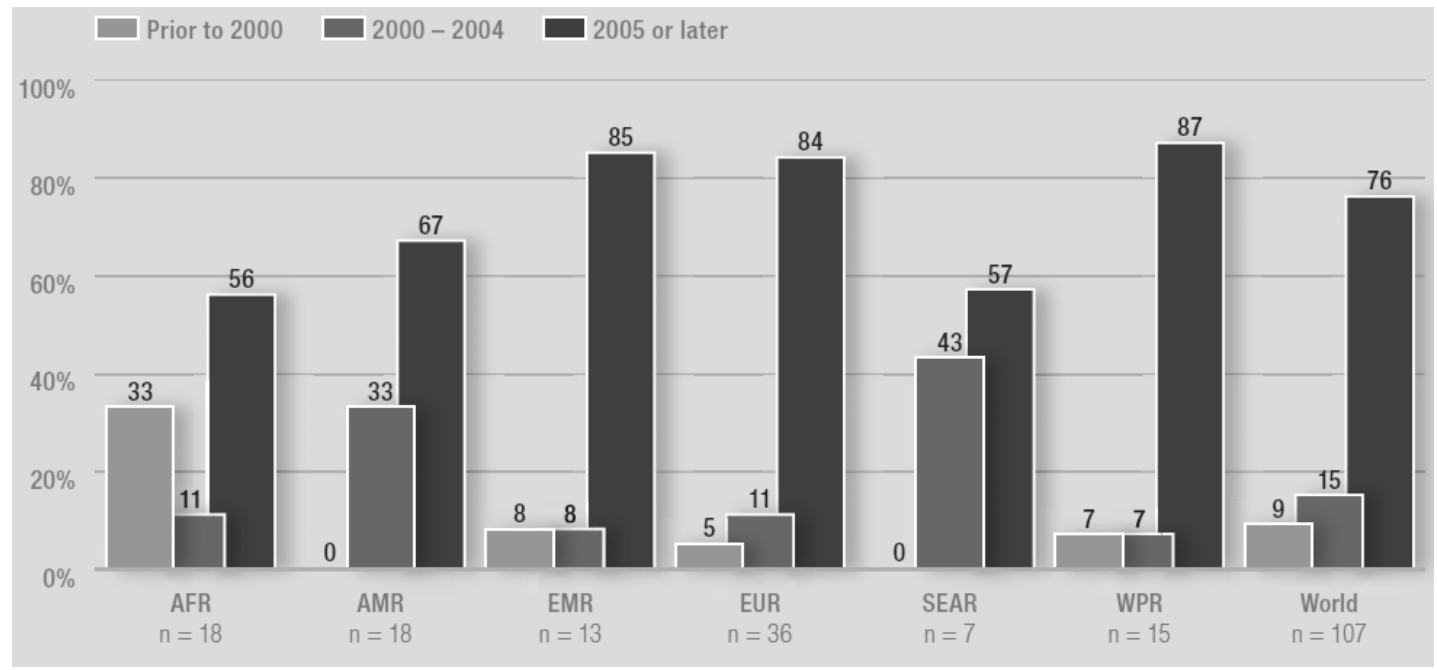

Fonte: Mental Health Atlas, 2011 (WHO, 2011).

A aprovação de legislação e as ações de redução de leitos psiquiátricos expressam, por um lado, o avanço da luta pela RP; por outro, evidenciam o embate entre os donos de HPs que se baseiam no modelo hospitalocêntrico e veem a loucura como "negócio" e os defensores do fim do HP. Como grande parte dos processos que almejam transformações práticas e defendem valores sociais, culturais e profissionais, este processo também apresenta muitos desafios, tensões e resistências (MELO, 2005). Diante disso, será retratada a seguir a trajetória da política de saúde mental no Brasil, a partir da Lei $10.216 / 2001$.

\section{O trajeto da Política de Saúde Mental no Brasil para redução dos leitos psiquiátricos}

A Política de Saúde Mental (Lei 10.216/2001) "tem como uma de suas principais diretrizes a reestruturação da assistência hospitalar psiquiátrica, objetivando uma redução gradual, programada e pactuada dos leitos psiquiátricos de baixa qualidade hospitalar" (BRASIL, 2011a, sp). Apesar de ser considerada um importante ganho para o Movimento de Reforma Psiquiátrica, essa lei traz elementos muito distantes do projeto original (do deputado Paulo Delgado). A extinção dos manicômios e a substituição por outros serviços foram substituídas pelo redirecionamento e pela política de proteção de direitos (LUZIO; YASUI, 2010).
A Lei 10.216/2001 define uma redução gradual, mas, somente em 2004, o Ministério da Saúde (MS) aprova a Portaria 52, que estabelece o Programa Anual de Reestruturação da Assistência Psiquiátrica Hospitalar no SUS (PRH). Nas considerações desta Portaria, o MS indica a "necessidade de estabelecer critérios técnicos para a redução progressiva de leitos, especialmente nos hospitais de maior porte, de modo a garantir a adequada assistência extra-hospitalar aos internos" (BRASIL, 2004, sp).

Um dos critérios usados é o redirecionamento dos recursos financeiros para a rede extra-hospitalar de saúde mental. Para impor essa redução de leitos, uma das propostas é a remuneração menor para os hospitais de maior porte. $^{2}$

Outro critério utilizado é a definição dos limites máximos e mínimos de redução anual de leitos para cada classe de hospitais. Assim, todos os hospitais com mais de duzentos leitos devem reduzir a cada ano no mínimoquarenta leitos. Os hospitais entre 240 e 360 leitos podem chegar a reduzir oitenta leitos ao ano (mínimo: quarenta), e os hospitais com mais de 360 leitos

\footnotetext{
${ }^{2}$ Os HPs de maior porte (acima de 160 leitos) receberão um valor que vai de $R \$ 31,33$ a $R \$ 27,56$ por leito - este valor, por exemplo, parao HPcom capacidade que igual ou superior a seiscentos leitos. Já os HPs de até 160 leitos (menor porte) receberão um valor por leito que varia de $R \$ 37,00$ a $R \$ 34,00$. À medida que os leitos diminuem, os HPs recebem diárias hospitalares maiores (BRASIL, 2004).
} 
podem chegar a reduzir, no máximo, 120 leitos ao ano (BRASIL, 2004). Ou seja, o PRH buscaprincipalmente a redução no porte dos hospitais, ou seja, daqueles com mais de 160 leitos, que, em longo prazo, deveriam ser transformados em hospitais de menor porte (BRASIL, 2004).

Observa-se que a redução dos leitos acontece nos hospitais públicos e privados conveniados ao SUS. Mas sempre houve maior concentração de leitos nos hospitais privados, principalmente após a década de 1970, quando ocorreu a intensificação da privatização da assistência médica. A diferença da quantidade de leitos públicos e privados de 1997 a 2003 expressa um processo ainda em andamento, mas que, aos poucos, vai obtendo resultados positivos.

Gráfico 2 - Evolução de leitos em hospitais públicos e privados

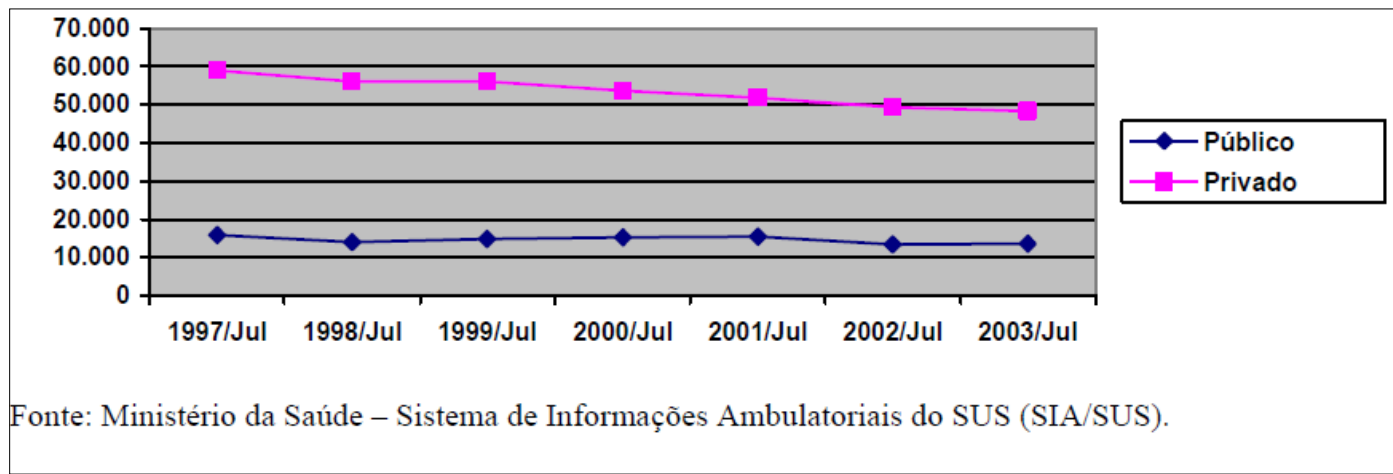

Em 2004, o número de leitos/SUS ocupados chegou a 45.194 (conforme Tabela 3), sendo que os HPPs concentravam - e ainda concentram - a maior quantidade de leitos e de investimento feito em saúde mental pelo SUS.

Tabela 3 - Diferença entre o número de leitos ocupados (SUS) entre HPs públicos e HPs privados

\begin{tabular}{c|c|c|c|c}
\hline \multirow{2}{*}{ Número de leitos ocupados* $^{*}$ Hosp. privados } & \multicolumn{3}{|c}{ Hosp. Públicos } \\
\cline { 3 - 5 } & & Hosp. Federal & Hosp. Estadual & Hosp. Municipal \\
\hline Até $\mathbf{4 0}$ & 1.670 & 131 & 574 & 398 \\
\hline $\mathbf{4 1 - 1 2 0}$ & 5.270 & 0 & 1.593 & 283 \\
\hline $\mathbf{1 2 1 - 2 0 0}$ & 10.287 & 183 & 1.513 & 210 \\
\hline Mais de 200 & 18.365 & 0 & 3.989 & 727 \\
\hline Total & 35.592 & 314 & 7.670 & 1.617 \\
\hline
\end{tabular}

* Leitos ocupados (média anual): dias de permanência divididos por 365 (dados consolidados para a Santa Casa de Nova Granada, Estado de São Paulo, que alterou a' razão social durante o exercício de 2004).

Fonte: Ministério da Saúde, 2004.

A partir desses altos índices de leitos concentrados nos hospitais privados, os defensores da RP esperavam que esse quadro fosse revertido por meio do $\mathrm{PRH}$. Mas essa reestruturação parte do princípio de que, à medida que se reduzem os leitos dos HPs, deve haver um aumento dos serviços comunitários e de base extra-hospitalar (como os Centros de Atenção Psicossocial - CAPS, Residências
Terapêuticas, Centros de Convivência e Cultura, entre outros). Esse aumento dos serviços extrahospitalares e a aceleração da desospitalização aconteceram entre os anos de 2002 e 2004, momento que foi caracterizado por Borges e Baptista (2008) como um momento de expansão. Foi um aumento significativo de serviços, porém insuficiente com relação à necessidade da 
demanda da população. O mapa de cobertura a seguir (Mapa 1) mostra como ainda há assimetrias regionais no Brasil, apesar do aumento dos serviços de atenção psicossocial em 2002, 2006 e 2011 (BRASIL, 2012).

Mapa 1 - Cobertura por municípios dos CAPS
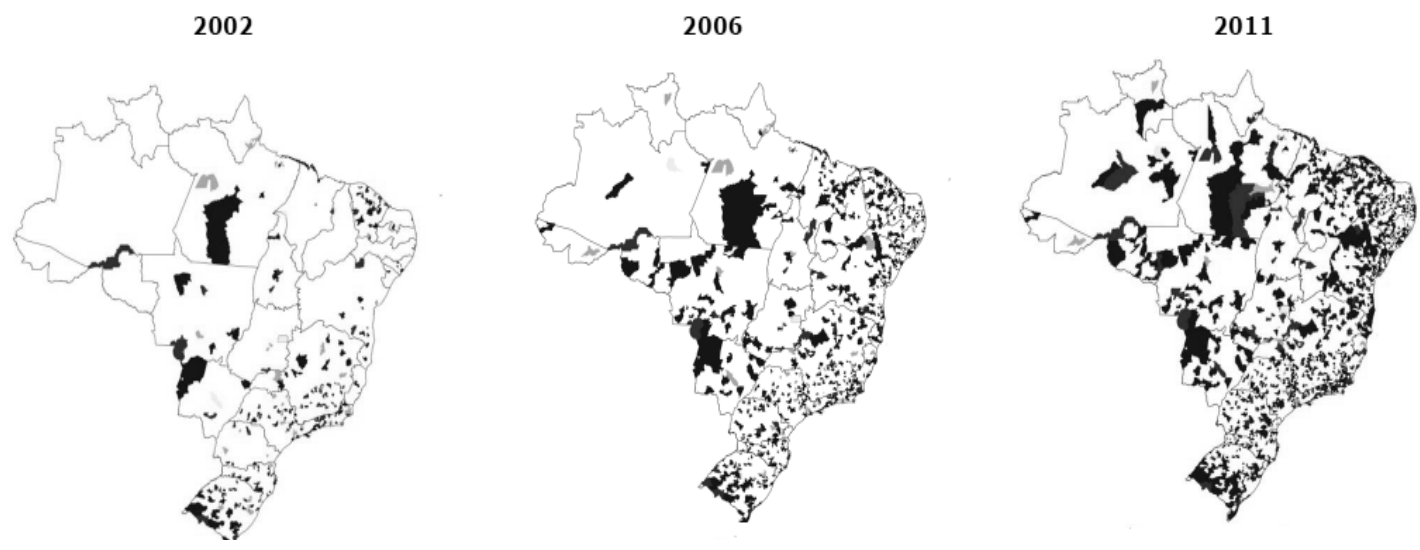

(parâmetro de 1 CAPS para cada 100 mil habitantes)

Fonte: Coordenação de Saúde Mental, Álcool e Outras Drogas/DAPES/SAS/MS, Instituto Brasileiro de Geografia e Estatística.

A escala em cinza indica a cobertura dos municípios (quanto mais escuro, melhor é a cobertura).

Além de ser desigual a quantidade de leitos em hospitais públicos e privados, é também desigual a sua distribuição entre as regiões do Brasil. Os leitos se concentram principalmente nos grandes centros urbanos e isso tem causado a desassistência aos pacientes com transtornos mentais nos locais com baixa quantidade de leitos. Outras consequências desse quadro são a migração dessas pessoas para outros estados e municípios e também a dificuldade na formulação e na condução da política de desospitalização (BRASIL, 2005).

O processo de redução de leitos e a consequente expansão dos serviços extra-hospitalares entram na lógica do processo de desinstitucionalização defendido pelo MRP, que tenta alcançar o deslocamento do tratamento dos pacientes com transtornos mentais do HP para esses serviços extra-hospitalares de base comunitária.

$\mathrm{Na}$ mesma direção, outro mecanismo que propõe mudanças no atual modelo de internação psiquiátrica é o Programa Nacional de Avaliação dos Serviços Hospitalares. O PNASH/Psiquiatria foi regulamentado pela Portaria 251/2002 etem como objetivos melhorar a qualidade da assistência dos serviços hospitalares prestados aos usuários do SUS e indicar os principais problemas na qualidade da assistência (BRASIL, s/d).

Esse programa realiza vistorias, avaliando anualmente todos os hospitais conveniados e públicos do SUS. Está dividido em duas partes: avaliação técnica e avaliação por parte dos usuários. A primeira avaliação engloba aspectos como estrutura física, limpeza e roupa da unidade hospitalar; alimentação; recursos humanos; enfermagem; projeto terapêutico; prontuários, entre outros. Já a segunda engloba dois formulários, que são respondidos pelos usuários de longa permanência (quando possível) e por aqueles que tiveram alta nos últimos sete dias (BRASIL, 2003).

A avaliação possui indicadores de qualidade, sendo que o hospital pode ser classificado como: a) excelente- aquele que deve ser mantido do jeito que está; b) bom-aquele que precisa melhorar;e c) regular; ruim ou péssimo. Os hospitais que tiverem resultado ruim precisarão de adequações e devem sofrer revistoria. Os péssimos são considerados de baixa qualidade e são encaminhados para o descredenciamento pelo MS (BRASIL, s/d). 
Após duas avaliações realizadas, os problemas recorrentes apontados no processo foram:

a) quanto ao projeto terapêutico - a maioria dos hospitais não possuía um projeto terapêutico para seus pacientes, ou o projeto apresentado não condizia com a prática institucional (BRASIL, 2007).

No ano de $2002,62,30 \%$ dos HPs foram avaliados como regulares e ruins e $14 \%$ como péssimos (ou seja, 76,3\% encontravam-se em condições inaceitáveispara o tratamento dispensado a seus usuários). Já em 2004, o número de hospitais avaliados como péssimos aumentou para $18 \%$, e regulares e ruins representaram $67,87 \%$, ou seja, passados dois anos, as condições pioraram;

b) recursos humanos -com relação ao número de profissionais, os HPs foram considerados insuficientes: $34 \%$ considerados péssimos, $17 \%$ ruins e $20 \%$ regulares;

c) Aspectos gerais da assistência - com relação à internação, o PNASH apontou que $62 \%$ dos hospitais apresentavam $20 \%$ ou mais de pacientes de longa permanência no ano de 2003.

Os três itens (projeto terapêutico, recursos humanos e assistência psiquiátrica) indicam que um longo caminho precisa ser percorridoentre a Lei 10.216/2001 e sua aplicabilidade, qual seja, a loucura não pode ser um negócio em detrimento dos direitos fundamentais do cidadão dito "louco".

Esses dados mostram que, em geral, os hospitais não trabalham com a reinserção social dos pacientes, podendo gerar um processo de cronicidade nessa população. Também não há esforço para melhorar a qualidade da assistência hospitalar prestada, visto que no decorrer das avaliações, os números demonstram que os HPs não apresentaram melhoras com relação aos critérios acima.

Por outro lado, outros resultados das avaliações nos HPs foram considerados positivos pelo MS: embora ainda insuficiente, houve redução de leitos. Entre 2002 e 2011, cerca de 19mil leitos psiquiátricos foram fechados por meio do $\mathrm{PNASH} /$ psiquiatria e do $\mathrm{PRH}$, e foi significativo o aumento de rede extra-hospitalar.

Gráfico 3 - Leitos Psiquiátricos SUS por ano (2002-2011)

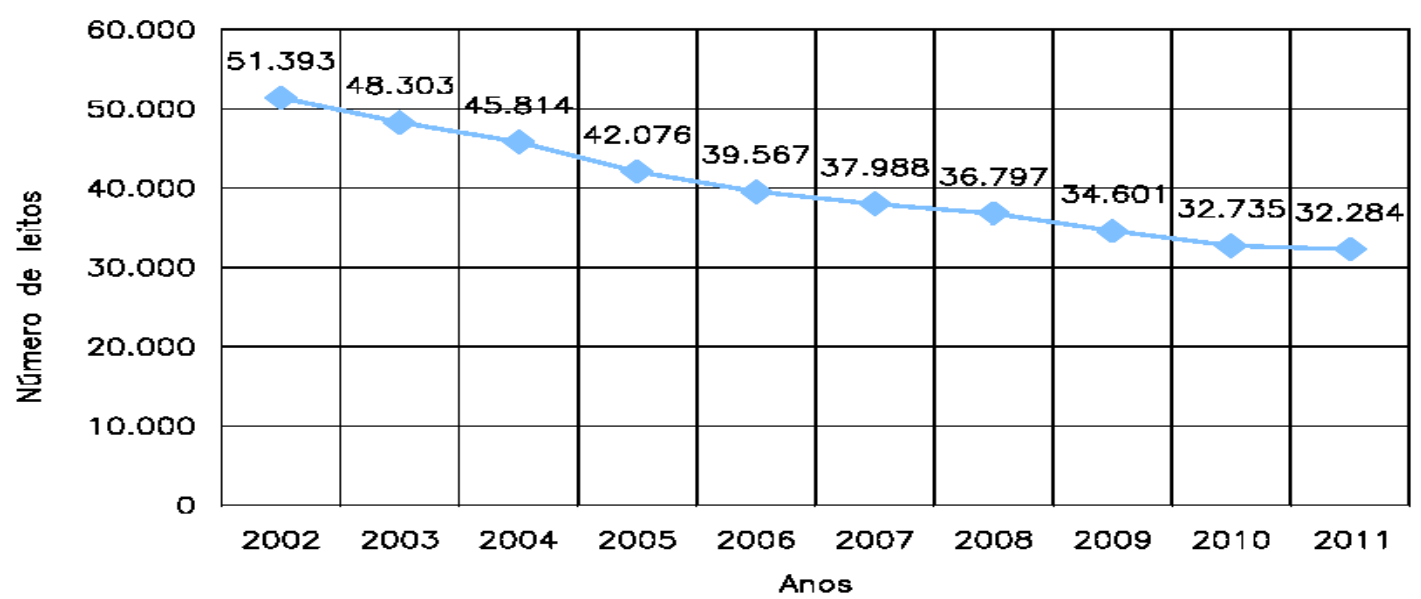

Fonte:SIH/SUS.Coordenação de saúde mental, álcool e outras drogas/DAPES/SAS/MS e coordenações estaduais. A partir de 2004, PRH/CNES e Coordenações Estaduais. 
Considerando o porte hospitalar, observa-se, na Tabela 4, que os hospitais de pequeno porte (até 160 leitos) são os que apresentam hoje o maior número de leitos. Em 2002, essa porcentagem era de $24 \%$, e, em 2010, de 48,67\%. Essa mudança é fundamental, pois contribui para a qualificação do atendimento, podendo reduzir problemas nos macro-hospitais como, por exemplo, isolamento, longo tempo de permanência e a baixa qualidade dos serviços prestados. Mas devem ser tomados os devidos cuidados para evitar que as pessoas fiquem desassistidas.

Tabela 4 - Mudanças do perfil dos hospitais psiquiátricos

\begin{tabular}{|c|c|c|c|c|c|c|c|c|c|}
\hline \multirow{3}{*}{ Ano } & \multicolumn{9}{|c|}{ Número de leitos } \\
\hline & \multicolumn{2}{|c|}{ Até 160} & \multicolumn{2}{|c|}{161 a 240} & \multicolumn{2}{|c|}{ De 241 a 400} & \multicolumn{2}{|c|}{ Acima de 400} & \multirow[t]{2}{*}{ TOTAL } \\
\hline & $\mathbf{N}$ & $\%$ & $\mathbf{N}$ & $\%$ & $\mathbf{N}$ & $\%$ & $\mathbf{N}$ & $\%$ & \\
\hline 2002 & 12.300 & 24,11 & 11.314 & 22,01 & 12.564 & 24,45 & 15.125 & 29,43 & 51.393 \\
\hline 2003 & 14.301 & 29,61 & 10.471 & 21,68 & 12.476 & 25,83 & 11.055 & 22,89 & 48.303 \\
\hline 2004 & 15.616 & 34,09 & 9.959 & 21,74 & 10.883 & 23,75 & 9.356 & 20,42 & 45.814 \\
\hline 2005 & 16.155 & 38,39 & 9.138 & 21,72 & 9.013 & 21,42 & 7.770 & 18,47 & 42.076 \\
\hline 2006 & 16.829 & 42,53 & 8.234 & 20,81 & 8.128 & 20,54 & 6.376 & 16,12 & 39.567 \\
\hline 2007 & 16.709 & 43,98 & 7.299 & 19,21 & 8.474 & 22,32 & 5.506 & 14,49 & 37.988 \\
\hline 2008 & 16.846 & 45,78 & 7.042 & 19,6 & 7.590 & 20,63 & 5.319 & 14 & 36.797 \\
\hline 2009 & 15.815 & 45,71 & 6.766 & 19,55 & 7.471 & 21,59 & 4.549 & 13,15 & 34.601 \\
\hline 2010 & 15.933 & 48,67 & 7.003 & 21,39 & 6.001 & 18,33 & 3.798 & 11,60 & 32.735 \\
\hline
\end{tabular}

Fonte: em 2002-2003,SIH/SUS, Coordenação de SM, Álcool e Outras Drogas/DAPES/SAS/MS e Coordenações Estaduais. A partir de 2004, PRH/CNES e Coordenações Estaduais (Brasil, 2011b).Obs: N representa a quantidade de leitos, e, \%, a porcentagem referente a essa quantidade.

Segundo o relatório de gestão 2007-2010, outro exemplo importante da redução dos leitos ocorreu entre 2003 e 2010, quando 29 hospitais foram indicados para descredenciamento pelo PNASH/Psiquiatria, mas somente quinze foram fechados. Aqueles que ainda não foram fechados estão sendo acompanhados e, na maioria dos casos, o não fechamento é resultado de ações judiciais (BRASIL, 2011a). O que ainda se observa nos HPs são as precárias instalações e serviços, além de ausência de projetos terapêuticos individualizados, a ênfase no tratamento medicamentoso e, na maioria das vezes, a cronificação e a dependência dos doentes mentais (BRASIL, 2005).
Cabe ressaltar que as avaliações feitas nos HPs necessitam da parceria entre as Secretarias Municipais e Estaduais de Saúde e entre os respectivos gestores, de acordo com o processo de descentralização que existe no SUS (BRASIL, s/d).

Exposto o panorama atual do processo de redução de leitos, é necessário colocar as resistências que ocorrem em relação a esse processo. Elas serão mostradas a seguir. 


\section{Resistências à mudança: a permanência dos Hospitais Psiquiátricos}

A resistência ao processo pode ser caracterizada por diferentes aspectos. O primeiro gira em torno da crítica da Associação Brasileira de Psiquiatria $(A B P)$ à Lei 10.216/2001. Essa lei é considerada antimédica - denuncia-se que os psiquiatras estão sendo cada vez mais excluídos da área de saúde mental.

Desde a implantação do PNASH/Psiquiatria, os defensores da RP têm se deparado com ações contrárias por parte da Federação Brasileira de Psiquiatria (FBH), da ABP e dos setores mais conservadores.

O segundo aspecto seria em relação às críticas à Política de Saúde Mental em vigor, feitas por opositores à RP. São elas relacionadas: a) à metodologia do PNASH- consideram errado e totalmente subjetivo o fato de os pacientes internados serem entrevistados e decidirem a pontuação final da avaliação; entrevistas por não médicos caracterizam exercício ilegal da medicina; a falta de comunicação prévia aos médicos assistentes de cada paciente,quando cometida por médico do SUS, caracteriza infração ao Código de Ética Médica. Destacam que a Portaria n.251/2002 ${ }^{3}$ e a classificação PNASH apresentam um desvio de finalidade, pois não visam a qualificar os hospitais ou adequá-los à Lei 10.216/2001, mas sim a reduzir leitos e desclassificar hospitais para depois descredenciá-los do SUS; b) à redução de leitos imposta no país - segundo a FBH e a ABP, há um déficit de leitos, segundo os parâmetros de necessidade do MS; c) à inadequação das exigências da PSM para os HPs e o pagamento realizado- opõem-se às avaliações do PNASH porque, segundo eles, a quantidade de recursos humanos, bem como as exigências dos HPs, não são compatíveis com os preços da tabela de procedimentos SIH/SUS ${ }^{4}$

\footnotetext{
${ }^{3}$ A portaria 251/02 refere-se ao "estabelecimento de diretrizes e normas para a assistência hospitalar em psiquiatria, reclassificando os hospitais psiquiátricos, definindo e estruturando a porta de entrada para as internações psiquiátricas na rede do SUS, e dá outras providências." (BRASIL, 2002, sp.).

${ }^{4}$ Refere-se a um conjunto de procedimentos utilizados para a remuneração de serviços ambulatoriais e hospitalares de prestadores contratados e conveniados ao SUS."A tabela de procedimentos SUS é constituída pela tabela de procedimentos do Sistema de Informações Ambulatoriais (SIA) e pela tabela de procedimentos
}

(FBH, 2004). Por exemplo: com base em um valor de $\mathrm{R} \$ 28,68$ por paciente/dia, um hospital com 240 leitos gastaria com os recursos humanos exigidos pela Portaria $251 / 2002^{5}$ do MS o valor de $\mathrm{R} \$ 209.638,98$. Porém, o faturamento máximo mensal é de $\mathrm{R} \$ 206.496,00$, ou seja, consideram que há um déficit de $\mathrm{R} \$ 3.142,98(\mathrm{FBH}, 2004)$.

Com tudo isso, a FBH deixa bem claro que os pacientes, os hospitais de psiquiatria e os profissionais saem prejudicados com a avaliação e a possível redução de leitos. Como consequência, apontam a desassistência e o desamparo dos doentes mentais, além da demissão de funcionários. Também acusam o Movimento de Luta Antimanicomial de, entre outras coisas, promover a contratação de funcionários sem a realização de concursos públicos (FBH, 2004).

A dita "desassistência" aos doentes mentais é retratada e denunciada por vários veículos de comunicação. No Rio de Janeiro, por exemplo, o jornal O Globo (2007) acusa as esferas do governo de não aplicar devidamente o dinheiro para a saúde mental, após o fechamento dos leitos psiquiátricos. A principal consequência disso seria o aumento do número de doentes mentais nas ruas e nas prisões. Entre as críticas, destacam-se: o investimento insuficiente na saúde mental, bem como na saúde em geral; a não aplicação dos recursos em uma rede extra-hospitalar; a falta de leitos psiquiátricos em hospitais gerais; e a falta de compromisso de algumas prefeituras, que deixam a desejar nos serviços prestados. Com isso, o processo que deveria se chamar desinstitucionalização passa a se chamar desospitalização e desassistência.

Seguindo essa reportagem, outra manchete enfatiza: "Sem hospícios, morrem mais doentes mentais". O jornal culpa o governo por se fecharem os leitos psiquiátricos e não se criarem os serviços substitutivos necessários, ficando os doentes mentais sem tratamento adequado, sem assistência, o que muitas vezes os leva àmorte. No entanto, o presidente da $A B P$ de então disse que a relação feita pelo jornal não

do Sistema de Informações Hospitalares (SIH)" (BRASIL, 2005, p. 374).

\footnotetext{
${ }^{5}$ Portaria GM/MS 251/02. Estabelece diretrizes e normas para a assistência hospitalar em psiquiatria, reclassifica os hospitais psiquiátricos, define e estrutura a porta de entrada para as internações psiquiátricas na rede do SUS e dá outras providências.
} 
foi comprovada (ABP, 2006). Considera-se que essas reportagens fazem críticas à política de redução de leitos psiquiátricos, expressando a existência de pontos de vista divergentes à RP.

Esse embate na área de saúde mental explicita o modelo dual assumido pela política de saúde brasileira (o Estado partilha com o mercado a execução dessa política). Campos (2008, $\mathrm{sp}$, grifos nossos) nos dá um grande exemplo desse embate entre público e privado:

No caso brasileiro [...] o sistema continuou bastante dependente dos hospitais privadose filantrópicos para assegurar atendimento aos cidadãos. Ainda hoje, somente $36 \%$ dos leitos do SUS são públicos (municípios, estados, universidades ou da União). Os outros $64 \%$ são de instituições particulares, que mesclam a clientela entre pagantes, afiliados ao sistema de saúde complementar e usuários do SUS. O sistema cresceu mais no atendimento ambulatorial e de urgência, assegurando o cuidado direto para $68 \%$ de seus dependentes. Podemos considerar que, ao contrário da estrutura portuguesa ou da inglesa, a nossa já nasceu com uma marca importante de privatização. Observe-se que o atendimento hospitalar e de alta ou média complexidade absorve $80 \%$ do financiamento. O restante destina-se a Atenção Básica e a Programas de Promoção e de Vigilância à Saúde.

Um embate envolve os recursos para a área hospitalar. No caso da saúde mental, os dados indicam que, desde 2006, os gastos com a área hospitalar diminuíram - e, consequentemente, aumentaram os gastos com serviços extra-hospitalares. Em 2011, foram destinados $71,2 \%$ de recursos SUS para serviços extra-hospitalares e $28,8 \%$ ficaram com gastos hospitalares (BRASIL, 2012).

A partir da redução dos leitos em HPs, denuncia-se o abandono a que estão sujeitas as pessoas com transtorno mental. Em torno desse argumento, aparecem os sujeitos que se encontram em situação de rua (ou na rua) e os usuários de crack. Além disso, a loucura aparece como uma ameaça à sociedade, expressando aqui uma histórica cultura baseada na exclusão e na crença do perigo que os loucos representam.

AABP propõe uma mudança no modelo de assistência psiquiátrica: que passe a ser integral, que não se resuma a um só serviço, como, por exemplo, os CAPS, e que tenham a capacidade de atender às necessidades dos pacientes (ABP, 2006). Com relação aos leitos psiquiátricos, dados do censo de 2010 do Instituto Brasileiro de Geografia e Estatística (IBGE) estimam que hoje haja necessidade de 180 mil deles.

$\mathrm{O}$ posicionamento da $\mathrm{ABP}$ em relação à diversidade de serviços e à qualidade na assistência prestada é também defendido pelo MRP e pela Política de Saúde Mental em vigor (e em conformidade com as diretrizes do SUS e a carta de direitos dos usuários do SUS). O ponto nodal é o lugar do HP nesse processo.

É comum que os sujeitos rotulados como doentes mentais, quando em situação de desassistência, passem a ser alvos de outros serviços públicos. Um campo que vem sendo convocado a intervir na questão da desassistência aos "loucos" é a Assistência Social.

De acordo com a Lei Orgânica de Assistência Social (LOAS), a Assistência Social é direito do cidadão e dever do Estado, e faz parte da Seguridade Social Brasileira de caráter não contributivo. Tem como objetivo prover os mínimos sociais, juntamente com a iniciativa pública e a sociedade, para poder garantir o atendimento às necessidades básicas, entre outros quesitos (BRASIL, 2005).

Os Centros de Referência da Assistência Social (CRAS) e os Centros de Referência Especializados da Assistência Social (CREAS), instâncias integrantes do Sistema Único da Assistência Social (SUAS), recebem cotidianamente demandas relacionadas à saúde mental ${ }^{6}$ (abandono, violência, maus-tratos etc.), sendo que a violação de direitos é muito presente.

Em muitos casos, chegam ao CRAS pessoas com transtorno mental ${ }^{7}$ que vivem nas ruas. A dificuldade dos técnicos para fazer o encaminhamento adequado daqueles que

\footnotetext{
${ }^{6}$ Dados de Silva (2004) indicam que $90 \%$ das crianças institucionalizadas no Brasil são filhos de pais envolvidos com consumo ou tráfico de drogas.
${ }^{7}$ Teixeira (2010) afirma que os profissionais do CRAS por ela en- trevistados indicaram como problemas dos usuários: falta de ren- -, falta de qualificação de mão de obra, problemas da saúde fí- sica e mental, além dos decorrentes de problemas com os filhos, sejam problemas escolares, de delinquência, uso de drogas, da, desemprego - ou informalidade, ou precariedade do trabalho violência, dentre outros.
} 
apresentam transtornos mentais é agravada pela inexistência de integração entre os CAPS e os serviços de assistência, pela expectativa de internação colocada por técnicos dessa política, por pressão de familiares, pelo Poder Judiciário e pela comunidade. Tudo isso muitas vezes tem levado os dispositivos da Assistência Social a defender - sem problematização - a internação compulsória. Garcia e Oliveira (2011), analisando a implementação da política de saúde mental no Espírito Santo, indicam a dificuldade - e os embates de perspectivas - entre os técnicos da Saúde Mental, os CRAS e o Judiciário.

Tanto o Ministério da Saúde quanto a ABP concordam que a crescente "judicialização" da assistência e a frequente confusão do Ministério Público entre direitos de cidadania e indicações terapêuticas dificultam o trabalho.

Estudos mostram que as principais razões para que os moradores de rua estejam nesta situação são, em primeiro lugar, o alcoolismo/drogas, com $35,5 \%$; em segundo lugar, o desemprego, com 29,8\%; e, por último, as desavenças familiares, com 29,1\% (BRASIL, s/d). Isso evidencia a grande relação dos dependentes de álcool e outras drogas - considerados doentes mentais com o morador de rua. Em decorrência disso, a Assistência Social, mesmo não sendo a principal política destinada a tratar dos pacientes mentais, acaba se tornando uma alternativa nesta situação de desassistência advinda da falta de expansão dos serviços extra-hospitalares.

Enfim, pode-se considerar que o processo de Reforma Psiquiátrica encontra muita resistência e não é um movimento hegemônico.

\section{Considerações finais}

Com o passar dos anos, avança a redução de leitos psiquiátricos no Brasil, que faz parte do Movimento de Reforma Psiquiátrica. Porém, esse processo enfrenta muitos desafios que impedem sua efetivação. Entre eles, estão a falta de investimentos e prioridades na área de saúde mental, a oposição constante da FBH, dos setores mais conservadores e da Indústria Farmacêutica, a desqualificação de leitos e a cultura da população em relação ao doente mental.

Para a efetivação da política de saúde mental, é necessário mudar esse quadro desfavorável. É imprescindível que haja a expansão da rede extra-hospitalar articulada à rede de saúde em todos os níveis de complexidade: suporte, serviços qualificados, tratamentos adequados $\mathrm{e}$ investimentos compatíveis com a área.

O projeto de intervenção do MS nos HPs - a partir do PNASH/Psiquiatria e do PRH - é importante, pois busca melhorar a qualidade da assistência hospitalar dada aos pacientes com transtornos mentais, bem como diminuir os leitos psiquiátricos em HPs, contribuindo para a desinstitucionalização e para a mudança do perfil desses hospitais, que passam a ter cada vez menos leitos psiquiátricos. Por outro lado, o embate é constante e nem sempre a indicação de fechamento de leitos resultou em supressão dessas vagas. É mister que o Serviço Social se coloque nessa frente, produzindo cada vez mais conhecimento que desnude essa realidade e defenda os princípios da RP.

Conclui-se que o cenário em que se insere o Movimento de Reforma Psiquiátrica é considerado desfavorável e desafiador. A RP brasileira caminha a passos lentos e a política de redução de leitos se apresenta como um instrumento favorável, mas, sozinha, sem garantia de financiamento, enfrenta todo tipo de dificuldade para avançar.

Algumas questões emergem a partir deste estudo: será possível efetivar os princípios da RP -desospitalização e ampliação da rede extra-hospitalar de base comunitária - em uma sociedade capitalista? É válido considerar que o processo de redução de leitos tem reafirmado esses princípios? As novas legislações em saúde mental estão caminhando nessa direção? E os HPs, que sempre ocuparam um papel central, deixarão de ser os principais responsáveis pelo tratamento psiquiátrico?

Assim, como linha de pesquisa, mais que respostas, nosso estudo produziu novas indagações - que são alvo de uma nova pesquisa com o apoio do CNPq.

\section{Referências}

ASSOCIAÇÃO BRASILEIRA DE PSIQUIATRIA et al. Diretrizes para um modelo de assistência integral em saúde mental no Brasil. 2006.Disponível em: <http://www.abpbrasil.org.br/diretrizes_final.pdf>. Acesso em: 7 set. 2011. 
.PG enfrenta caos na saúde mental.Faltam psiquiatras, leitos e políticas públicas voltadas ao atendimento das famílias de pacientes com transtornos mentais. 2009. Disponível em: $<$ http://www.abpbrasil.org.br/medicos/clipping/ exibClipping/?clipping=9711 $>$. Acesso em: $22 \mathrm{fev}$. 2012.

AMARANTE, P. Uma aventura no manicômio: a trajetória de Franco Basaglia. Hist. cienc. saúdeManguinhos, out. 1994, v.1, n.1, p.61-77.

Loucos pela vida: a trajetória da reforma psiquiátrica no Brasil. Rio de Janeiro: Ed. Fiocruz, 1995.

BASAGLIA, F. A instituição negada: relato de um hospital psiquiátrico. 2.ed. Rio de Janeiro: Graal, 1991.

BORGES, C. F.; BAPTISTA, Tatiana W. F. O modelo assistencial em saúde mental no Brasil: a trajetória da construção política de 1990 a 2004. Cad. Saúde pública, n.24, v.2, p.456-68, fev. 2008.

BRASIL. Presidência da República. Lei Orgânica da Assistência Social, Lei n.8.742, de 7 de dezembro de 1993, publicada na DOU de 8 de dezembro de 1993.

Presidência da República. Emenda Constitucional $\mathbf{n}^{\circ} \mathbf{2 9}$, de 13 de setembro de 2000 , publicada na DOU de 14 de setembro de 2000.

Ministério da Saúde. Lei 10216. Brasília: DF, 2001. Disponível em:<http://www.planalto.gov. br/ccivil_03/Leis/LEIS_2001/L10216.htm>. Acesso em:31 out.2013.

Ministério da saúde. Programa nacional de avaliação dos Serviços hospitalares - pnash:versão hospitais psiquiátricos. Brasil, 2003.

Ministério da Saúde. Portaria 52. Brasília: DF, 2004. Disponível em:<http://dtr2001.saude.gov.br/ sas/PORTARIAS/Port2004/GM/GM-52.htm>. Acesso em 20set. 2011.

.Tribunal de Contas da União. Avaliação das Ações de atenção à Saúde Mental: Programa de Atenção à Saúde de Populações Estratégicas e em situações especiais de agravos. Brasília, 2005.

Ministério da Saúde. Secretaria de Atenção à Saúde/DAPE. Saúde Mental no SUS:acesso ao tratamento e mudança do modelo de atenção. Relatório de Gestão 2003-2006. Brasília, janeiro de 2007.
.Ministério da Saúde. SUS de Aa Z: garantindo saúde nos municípios. 3.ed. Brasília, 2009

.Instituto Brasileiro de Geografia e Estatística - IBGE. Pesquisa de Assistência Médico-Sanitária. Brasília, 2009a.

Ministério do Desenvolvimento Social e Combate à Fome. Sistema Único de Assistência Social. Proteção Social Básica. Orientações Técnicas Centro de Referência de Assistência Social- CRAS. Brasília 2009b.

.Ministério da Saúde.Saúde Mental no SUS as novas fronteiras da Reforma Psiquiátrica. Relatório de Gestão 2007-2010. Brasília,jan.2011a.

Ministério da Saúde. Saúde Mental em Dados 8. Ano VI, n.8. Informativo Eletrônico. Brasília: janeiro de 2011b.

.Ministério da Saúde. Saúde Mental em Dados 10. Ano VII, n.10. Informativo Eletrônico. Brasília: mar. 2012.

Ministério da Saúde. Pnash psiquiatria e programa de reestruturação da assistência Disponível em: <http://portal.saude.gov.br/portal/ saude/visualizar_texto.cfm? idtxt=31354>. Acesso em:19 set. 2011 a.

Ministério do Desenvolvimento Social e Combate à Fome. População em situação de rua. Disponível em: <http://www.mds.gov.br/ falemds/perguntas-frequentes/assistencia-social/ pse-protecao-social-especial/populacao-de-rua/ populacao-em-situacao-de-rua>. Acesso em: 2 nov. 2012.

CAMPOS, G. 0 público e o privado na saúde brasileira. 2008. Disponível em: <http://www. diplomatique.org. br/artigo.php?id=174\&PHPSESS $\mathrm{D}=099$ cbc670a7e8a6c998a4f532aaf76c9>.Acesso em:6 abr. 2012.

CARVALHO, G. Gasto com saúde no Brasil em 2009. Disponível em: <observasaude.fundap.sp.gov. br/saude2/sus/Acervo/GS_Br_2009.doc>. Acesso em: 22 maio 2012.

A presença e participação do município na Ic 141: nova regulamentação do financiamento da saúde no Brasil. Disponível em:<http://www.idisa. org.br/site/documento_7235_0_2012---27---610--domingueira---financiamento-da-saude---204a..html>. Acesso em: 15 mar. 2012. 
CARVALHO, J. A.O governo não quer saber de quem ouve vozes. In: Jornal o Globo. São Paulo, p.15. Dezembro de 2007. Disponível em:<http://www.abp. org.br/newsletter/rep_oglobo2/>. Acesso em: 13 mar. 2012.

CONSELHO REGIONAL DE MEDICINA. Psiquiatria: a realidade da assistência ao doente mental no Estado do Rio de Janeiro (edição resumida)/contribuição e pesquisa do IESC/UFRJ. Rio de Janeiro: CREMERJ, 2007.

FEDERAÇÃO BRASILEIRA DE HOSPITAIS. Faturamento máximo mensal de hospital com 240 leitos ocupação 100\%.Psiquiatria hospitalar.Revista do Departamento de Psiquiatria da Federação Brasileira de Hospitais. Rio de Janeiro, out.2004 Ano I. sp. Disponível em:<http://www.psiquiatriageral.com. br/legislacao/psiquiatria_hospitalar_revista_pag06. htm>. Acesso em:4 nov. 2011.

GARCIA, M.L.T. O financiamento da Saúde Mental após o Pacto da Saúde. Libertas, v.11, n.2, 2011Disponívelem: <http://www.editoraufjf.com.br/ revista/index.php/libertas/article/view/1667>. Acesso em: 30 out. 2012.

GARCIA, M. L. T; OLIVEIRA, E., F. A. O. A política de saúde mental no estado do Espírito Santo. Revista Katálysis, v.14, n.1, Florianópolis,jan./jun., 2011.

KILSZTAJN, S. et al. Leitos hospitalares e reforma psiquiátrica no Brasil. Cad. Saúde Pública [online]. 2008 , v. 24 , n.10, p. 2354-62.

LUZIO, C. A.; YASUI, S.Além das portarias: desafios da política de saúde mental. In: Psicologia em Estudo, v.15, n.1, p. 17-26, jan/mar.2010.

MARQUES, R. M.; FERREIRA, M. R. J. Financeirização: impactos nas prioridades de gasto do Estado- 1990 a 2007. In: (Org.). O Brasil sob a nova ordem-a economia brasileira contemporânea - uma análise dos governos Collor a Lula. 1.ed. São Paulo: Saraiva, 2009, v.1. p.51-74.

MARQUES, R. M.; MENDES, Á. A saúde pública sob a batuta da nova ordem. In: MARQUES, R. M.; FERREIRA, M. R. J. (Org.). O Brasil sob a nova ordem-a economia brasileira contemporânea - uma análise dos governos Collor a Lula. 1.ed. São Paulo: Saraiva, 2009, v.1. p.267-86.

MELO, T. K. G. B. A reforma psiquiátrica no atual contexto da globalização. São Luis - MA, 2005. Disponível em: <http://www.joinpp.ufma.br/jornadas/ joinppll/pagina_PGPP/Trabalhos2/Thais_Karina_ Guedes_Bezerra.pdf>. Acesso em: 19 set. 2013.
MENDES, Á. O orçamento da saúde está sendo engolido pela política econômica do governo federal. Disponível em: <http://www.idisa.org.br/site/ documento_7235_0_2012---27---610---domingueira--financiamento-da-saude---204a..html>. Acesso em: 15 mar. 2012.

OMS. Saúde mental: nova concepção, nova esperança. Relatório Mundial da Saúde. 2002. Disponível em: <www.who.int/entity/whr/2001/en/ whr01_djmessage_po.pdf >. Acesso em: 21 set. 2011.

OLIVEIRA, C. L.O pensamento de Franco Basaglia na área da saúde mental. Disponível em: <http:// www.encontro2011.abrapso.org.br/trabalho/view?ID_ TRABALHO=1084>.Acesso em: 24 abr. 2012.

SANTOS, N.; CARVALHO, G. A regulamentação da EC-29: em busca do que é central no debate. Disponível em: <http://www.idisa.org.br/site/ documento_6618_0_2011---27---596---domingueira-financiamento-da-saude---200a..html>. Acesso em: 10 abr. 2012.

SILVA, E. R. A. O direito à convivência familiar e comunitária: os abrigos para crianças e adolescentes no Brasil. Brasília, DF: IPEA/CONANDA, 2004.

TEIXEIRA, S. O. Trabalho Interdisciplinar nos CRAS: um novo enfoque e trato à pobreza? Textos \& Contextos (Porto Alegre), v.9, n.2, p.286 -97, ago./ dez. 2010.

WORLD HEALTH ORGANIZATION (WHO). Mental Health Atlas 2011.Genebra, 2011. Disponível em: <http://whqlibdoc.who.int/ publications/2011/9799241564359_eng.pdf>. Acesso em: 31out. 2012. 